\title{
Escritas, leituras, visualidades: povoamentos para pensar a aula (ou a docência) como zona de pesquisa
}

Writings, readings, visualities: populations to think lessons (or teaching) as research zone

Cristian Poletti Mossi ${ }^{1}$

Faculdade de Educação da UFRGS

\section{Resumo}

A escrita deste texto insurge de uma zona entre dois projetos de pesquisa coordenados pelo seu autor, um já finalizado em dezembro do ano de 2015 e um iniciando suas atividades. Ambas as ações investigativas propõem aula, docência e pesquisa como instâncias de produção e criação que se cruzam e se de-formam (TADEU, 2000) entre escritas, leituras e visualidades. Nesse sentido, o texto é composto por três notas. A Nota 1 trata da aula como zona que possibilita o aparecimento, ou presentificação de docências. A Nota 2 inter-relaciona docência e pesquisa como zonas inseparáveis. E a Nota 3, compreendida no texto como uma nota transversal às duas anteriores, problematiza escrita, leitura e visualidades como potências para o pensamento enquanto inauguração do novo e não como mera recognição (DELEUZE, 2003a, 2003b, 2006).

Palavras-chave: Aula, Docência, Pesquisa, Escrita/Leitura, Visualidades.

\section{Abstract}

The writing of this text comes from a zone between two research projects coordinated by its author, one of them already concluded in December 2015 and the other starting its activities. Both investigative actions propose lesson, teaching and research as production and creation instances that intersect and de-form each other (TADEU, 2000) between writings, readings and visualities. In this sense, the text is composed of three notes. Note 1 deals with lessons as a zone that allows the appearance, or presentification, of different ways of teaching. Note 2 interrelates teaching and research as inseparable zones, and Note 3, understood in the text as a transverse note to the previous two, problematizes writing, reading and visualities as potencies for thought as inauguration of the new, and not as mere recognition (DELEUZE, 2003a, 2003b, 2006).

Keywords: Lesson, Teaching, Research, Writing/Reading, Visualities.

\section{PARTE I}

\section{Zonas}

Revista Digital do LAV - Santa Maria - vol. 9, n. 2, p. 61 - 74. - mai./ago. 2016 ISSN 1983 - 7348 http://dx.doi.org/10.5902/1983734823513 
Zona: s.f. Região; área demarcada naturalmente ou de modo artificial. Faixa; extensão territorial delimitada ${ }^{1}$.

Dois projetos de pesquisa, um já concluído e outro tão-somente começando, constituem as materialidades com as quais este texto se arranja. Compõem, pois, as zonas sobre as quais se pensa a aula (ou a docência) como espaços potentes para a pesquisa e para a criação, atravessadas por escritas, leituras e visualidades ${ }^{2}$ enquanto potências para o pensamento como inauguração do novo e não associado à mera recognição (DELEUZE, 2003a, 2003b, 2006).

O primeiro, já finalizado, intitulado Docência, criação e pesquisa - articulando produção de pensamento e de visualidades em educação das artes visuais, foi coordenado por mim de março de 2015 a dezembro de 2015, quando, na ocasião, trabalhava como professor adjunto do curso de Artes Visuais: Licenciatura da Universidade Estadual do Rio Grande do Sul (UERGS), ministrando disciplinas de Desenho (I e II) e Linguagem e Expressão Pictórica (I e II).

O segundo, também coordenado por mim - porém agora como professor adjunto do Departamento de Ensino e Currículo (DEC) da Faculdade de Educação (Faced) da Universidade Federal do Rio Grande do Sul (UFRGS) e ministrando as disciplinas de Estágio (I e II) em Artes Visuais para o curso de Licenciatura em Artes Visuais dessa instituição -, intitula-se Docência e criação em educação das artes visuais: povoamentos entre visualidades, leituras e escritas. O mesmo fundamenta seus objetivos e questões investigativas em algumas das problematizações que foram possíveis em relação ao primeiro projeto e iniciou suas atividades em maio de 2016 , tendo sua finalização prevista apenas para dezembro de 2018.

\section{Dimensões}

Ambos os projetos citados têm em comum a compreensão do espaço/tempo da aula (ou da docência) como lugar, ou lugares, de pesquisa e, por isso, de criação. As notas que formulam esse texto, portanto, se escrevem/leem por três vias (ou dimensões das zonas supracitadas) pensadas no exercício dos dois projetos mencionados, as quais se entrecruzam:

a) A primeira entende aula e docência como duas faces de um mesmo plano que se dobra e redobra sobre si mesmo constantemente. Ou seja, é no ambiente das

\footnotetext{
${ }^{1}$ Disponível em <http://www.dicio.com.br/zona/>. Acesso em: maio 2016.

${ }^{2}$ A noção de visualidade seria mais ampla que a noção estrita de imagem, pois, além de ocupar-se de questões estruturais/estilísticas/semióticas daquilo que se materializa visualmente em nossa contemporaneidade, também atesta as imagens como local de onde emergem "espaços dialógicos nos quais se inscrevem narrativas, trajetórias e histórias que, de alguma maneira, nos interpelam, desalojam e instigam fazendo perguntas que nos mobilizam em busca de explicações ou respostas" (MARTINS, 2009, p. 99).
} 
aulas, em sua preparação e nas reverberações possíveis a partir do espaço/tempo de uma aula onde se presentifica uma docência. Docência esta que nada tem a ver com um sujeito onisciente, mas com um acontecimento que está aquém e além de indivíduos racionais e bem formados. Aulas que "não são meros instrumentos dos professores", mas que de fato "os constituem" (CORAZZA, 2012, p. 28). Não é a docência que faz aparecer uma aula, mas a aula é que faz aparecer um docente. A docência se produz na aula e pela aula. Portanto, sempre que utilizado o pronome "um/uma" nessa escrita, indica não unidade, mas singularidade, liberação do "acontecimento naquilo que ele tem de não formado, e de não efetuável por pessoas" (DELEUZE; GUATTARI, 2012, p. 55).

b) A segunda entende, portanto, aula e docência como planos, campos, camadas ou, conforme optei por me referir neste texto, como zonas inseparáveis da noção de pesquisa e da noção de criação, já que "todo professor é um pesquisador; possui um espírito pesquisador; entra em devires-pesquisadores, enquanto educa" (CORAZZA, 2013, p. 94) e integra, justamente no ambiente das aulas que fazem com que essa docência se atualize e apareça, "uma tipologia das ações que são feitas com, entre, acerca, junto, no encontro com humanos" (CORAZZA, 2013, p. 94). O docente que pesquisa também é o docente que cria, pois "para educar, pesquisamos, procurando e criando, para ensinar; ensinamos, pesquisando, para procurar e, também, para criar" (CORAZZA, 2013, p. 97).

c) A terceira, a qual codifica e descodifica (DELEUZE; GUATTARI, 2011) em vetores de territorialização, desterritorialização e reterritorialização (idem), aula, docência e pesquisa, compreende escrita, leitura e visualidades como potências que, em diálogo ou em tensionamento (nunca em relação ilustrativa ou representacional), produzidas pelo próprio professor ou tomadas de outros e traduzidas, conforme propõe Corazza (2012, 2013), atravessam e povoam aula/docência e, dessa maneira, as constituem em meio a signos (no sentido deleuzeano) que nos forçam a pensar (DELEUZE, 2003b) ${ }^{3}$ e "a procurar sentidos, sem esquecer que o sentido encontrado é sempre menos importante do que o estado de procura em que o signo nos coloca" (FEIL, 2012, p. 63).

\section{Notas}

O texto que segue se compõe, assim, por notas. Notas de um pensamento inacabado, notas de continuidade entre um e outro projeto. Atesto, dessa forma, que não é meu objetivo aqui falar dos projetos em si, de seus intuitos e possíveis resultados estritos,

\footnotetext{
3 Deleuze (2003, p. 91) aponta que a gênese do ato de pensar "implica alguma coisa que violenta o pensamento, que o tira de seu natural estupor, de suas possibilidades apenas abstratas".
}

Revista Digital do LAV - Santa Maria - vol. 9, n. 2, p. 61 - 74. - mai./ago. 2016 ISSN 1983 - 7348 
mas sim de um entre, de uma zona de vizinhança que se propaga em meio às duas ações investigativas.

Para tanto, primeiramente (Nota 1), menciono uma atividade feita em uma de minhas aulas atuais, a qual, além de produzir uma espécie de encadeamento entre um projeto e outro, gerou também inúmeras problematizações para que fosse possível pensar a aula (ou a docência) como lugar de pesquisa (Nota 2) povoada por escritas, leitura e visualidades (Nota 3).

A noção de zona já anteriormente mencionada, nesse sentido, é cara a esse texto. Zona como território forjado, como extensão composta por formas de conteúdo e expressão tais como as definem Deleuze e Guattari (1995), enquanto misturas de corpos e de expressos incorporais ${ }^{4}$. São entendidas como zonas aqui os projetos a que me refiro, mas também a amálgama indissociável aula-docência-pesquisa. É desse lugar movediço que contém apenas linhas de ruptura e de continuidade que as notas a seguir insurgem e se entrelaçam. Notas que buscam propor pensar a aula (ou a docência) como zona de pesquisa e, por que não, de criação. Uma zona que maneja escritas, leituras e visualidades como ações e matérias que engendram constelações as quais dizem de uma formação singular - mais uma de-formação (TADEU, 2004), talvez, já que busca uma individuação sempre em processo antes da perseguição a um ideal estável ou uma forma plenamente acabada.

\section{PARTE II}

\section{Nota 1. Uma (boa) aula}

Aula de Estágio em Artes Visuais I (EAV I) do curso de Licenciatura em Artes Visuais da UFRGS. Os acadêmicos das turmas A e C para as quais ministro essa disciplina, repletos de inseguranças sobre o exercício da docência, sobre quais maneiras de produzir uma aula que seja significativa para estudantes de Ensino Fundamental e Médio, agora seus alunos. De onde vêm as ideias para uma aula? O que é importante que aconteça em uma aula para que ela seja considerada "boa"? Como não nos tornarmos os professores que criticamos? O que temos aprendido com as aulas de Estágio na Universidade e nas Escolas para nossas docências? Como nos inserimos como professores de Artes Visuais no momento que chamamos de contemporaneidade? Questões, questões, questões...

\footnotetext{
4 "A forma de expressão será constituída pelo encadeamento dos expressos, como a forma de conteúdo pela trama dos corpos. Quando o punhal entra na carne, quando o alimento ou o veneno se espalha pelo corpo, quando a gota de vinho é vertida na água, há mistura de corpos; mas os enunciados 'o punhal corta a carne', 'eu como', 'a água enrubesce', exprimem transformações incorpóreas de natureza completamente diferente (acontecimentos)" (DELEUZE; GUATTARI, 1995b, p. 28).
} 
Uma aula, assim como uma docência, parece ser inseparável, tal como a pesquisa, de problemáticas infindáveis que, ao invés de respostas, encontram mais e mais dúvidas. Em minhas aulas, entendidas como um dos campos de estudo de ambos os projetos já mencionados anteriormente, tenho procurado olhar para essas questões não como entraves, mas como combustível mobilizador de uma vida profissional que se dá em meio a uma natureza que é antes de tudo investigativa.

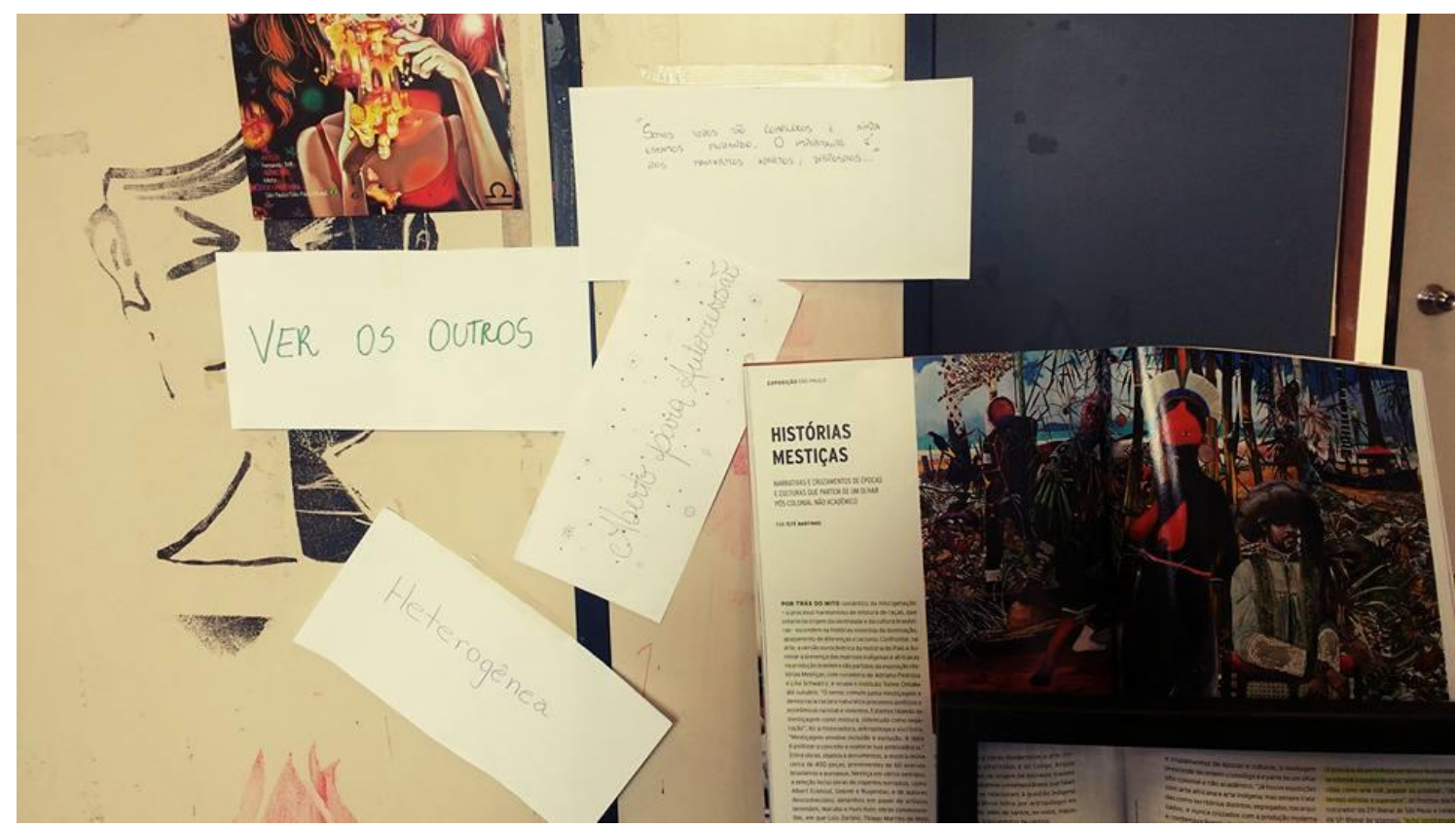

Figura 01 - Constelação afetiva (detalhe). Fotografia do autor, 2016.

Em uma data específica, tínhamos em nosso cronograma de estudos o conteúdo "Arte Contemporânea e Ensino das Artes Visuais". Partimos dos significados que cada um atribuía ao contemporâneo, para só então pensarmos especificidades de certas produções que chamamos de arte em nossa cultura e sociedade ocidentais em relação a seus possíveis impactos em práticas pedagógicas. Propus, nesse sentido, que cada um trouxesse para a aula uma visualidade (não necessariamente dita artística) que não respondesse objetivamente, mas movimentasse a questão: para você, o que é o contemporâneo?

Giorgio Agamben, filósofo italiano, em seu ensaio O que é o contemporâneo? (2009) afirma que o contemporâneo trata de uma forma de relação muito singular com o tempo, de modo a condescender a este, mas, ao mesmo tempo, dele tomar distâncias. Conforme o autor (2009, p. 59) o contemporâneo "é a relação com o tempo que a este adere através de uma dissociação e um anacronismo" (grifo do autor). Ou seja

Revista Digital do LAV - Santa Maria - vol. 9, n. 2, p. 61 - 74. - mai./ago. 2016 ISSN 1983 - 7348 
Aqueles que coincidem muito plenamente com a época, que em todos os aspectos a esta aderem perfeitamente, não são contemporâneos porque, exatamente por isso, não conseguem vêla, não podem manter fixo o olhar sobre ela.

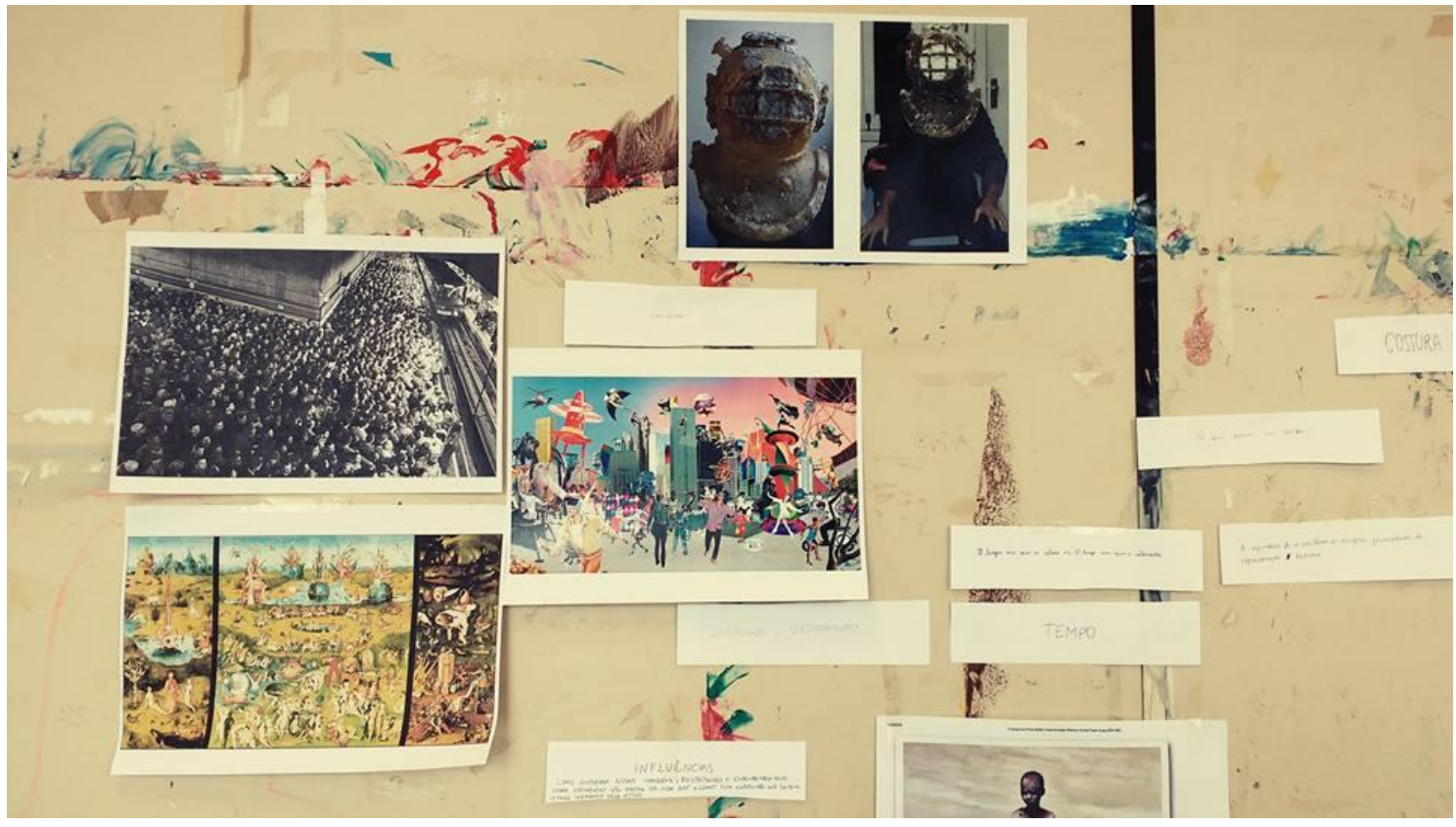

Figura 02 - Constelação afetiva (detalhe).

Fotografia do autor, 2016.

Nesse sentido, antes de nos aproximarmos de concepções já estruturadas e, de certa maneira universais, gerais por demais, sobre contemporaneidade, arte contemporânea, ensino de artes visuais, dentre outras noções e categorias, um olhar mais atento às singularidades e às tramas que possibilitavam que certas coisas fossem afirmadas naqueles coletivos se fez muito produtivo.

Na própria parede da sala de aula, fomos montando algo que chamei de constelação afetiva com as imagens trazidas pelos acadêmicos. Cada um, de posse de sua visualidade, foi colando-a no espaço determinado para a atividade e estabelecendo relações com as imagens dos colegas através de afinidades puramente sensíveis, afetivas (ou seja, como cada um se via diante de cada visualidade e do conjunto que ia se formando?). Alguns escritos também ajudaram a compor a constelação em forma de questões e de palavras não só em relação àquela aula específica, mas também sobre os conteúdos de outras aulas, sobretudo leituras já discutidas em outras práticas, que de algum modo produziam conexão com aquela produção. 
Essa atividade insurge em meio às linhas desse texto não como exemplo a ser seguido, tampouco como método a se repetir, mas como aparecimento de uma zona de problematização acerca das docências que se formulam no espaço/tempo mencionado (a aula), circunstancialmente, como plataforma para pensar, sobretudo, os imbricamentos entre essas duas instâncias que, conforme já dito, são aqui entendidas como duas faces de um mesmo plano: aula e docência.

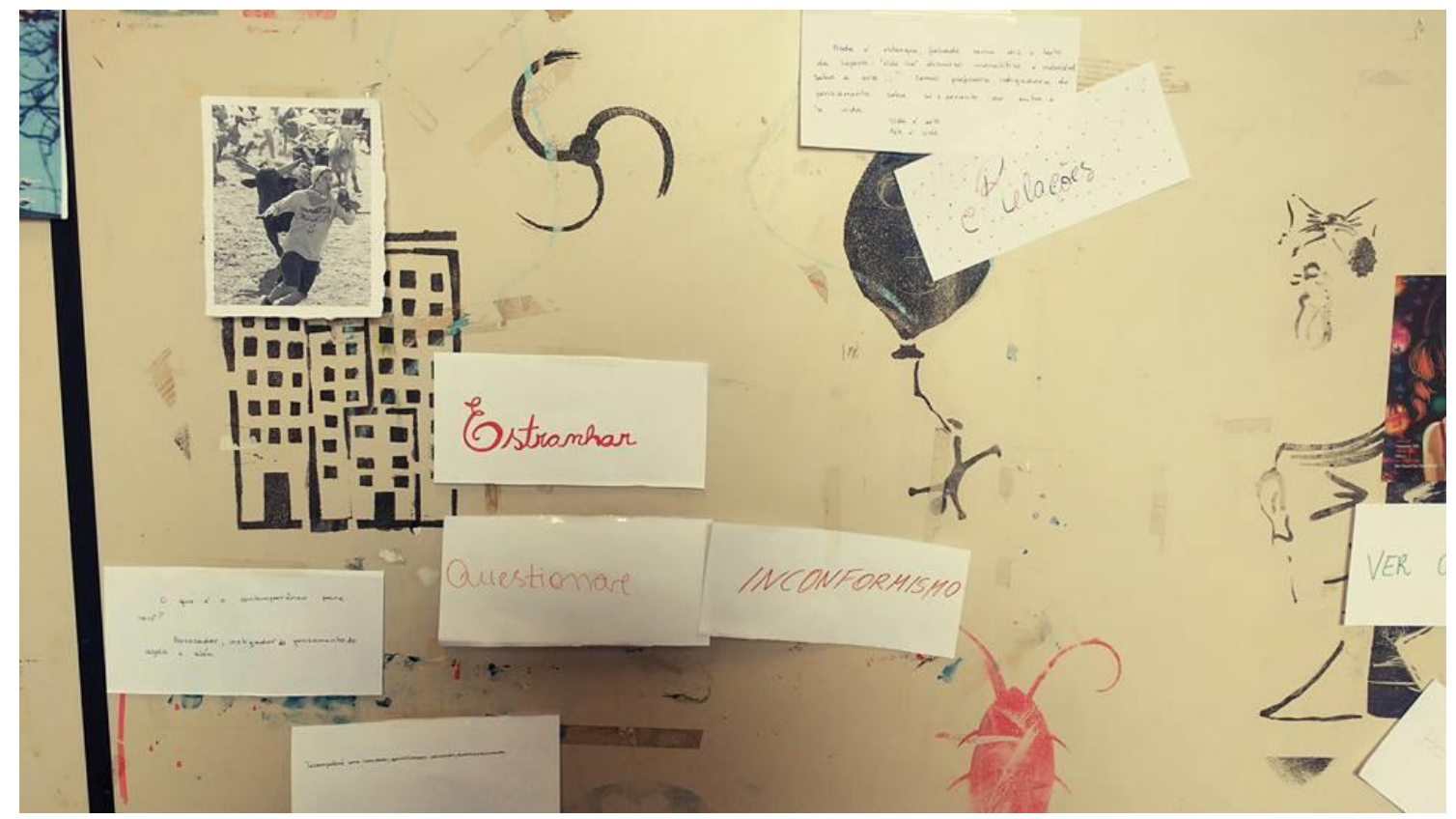

Figura 03 - Constelação afetiva (detalhe). Fotografia do autor, 2016.

Com Corazza (2013, p. 24), alego que podemos considerar uma aula brilhante "[...] pelo fato de que, hoje, neste dia determinado, nesta aula específica", o professor, em conjunto com os seus alunos, conseguiu

[...] formular algo novo para pensar; problematizar [...] o que até então não era considerado problemático por ninguém; conseguiu levar os alunos a encararem as besteiras e desaprender as verdades, que Ihes haviam sido transmitidas e ensinadas, e que eles haviam assimilado; para, desse modo, aprender algo que não fosse senso comum nem opinião.

Nesse sentido, as leituras feitas para aquela aula específica e para outras, as quais se mostraram nas palavras e questões escritas para compor a constelação afetiva e para propor a curadoria e as articulações entre as imagens, também ajudaram a povoar a aula (e/ou as docências) como multiplicidades (DELEUZE; GUATTARI, 2011) no contraponto 
de uma unidade significante (conteúdos apreendidos, sujeitos formados e sabedores de determinado assunto, interpretações corretas sobre certo texto).

Uma multiplicidade não tem nem sujeito nem objeto, mas somente determinações, grandezas, dimensões que não podem crescer sem que mude de natureza (as leis de combinação crescem então com a multiplicidade). [...] Um agenciamento é precisamente este crescimento das dimensões numa multiplicidade que muda necessariamente de natureza à medida que ela aumenta suas conexões (DELEUZE; GUATTARI, 2011, p. 23-24).

Cada coletivo, nesse sentido, respondeu a ação de uma forma singular, específica, selecionou certos motes para problematizar, se abriu para diferentes possibilidades de continuidade. Não porque cada um "É" um (ser, sujeito acabado), mas porque cada um se mantém em devir como condição de seu "próprio ser" (CORAZZA, 2013, p 128), correspondendo o indivíduo, assim, a "apenas uma das fases" (idem) do ser. Importou, nesse sentindo, não um espelhamento ou reconhecimento em relação às visualidades apresentadas ou às escritas/leituras que compuseram a constelação, mas como as relações entre tais artefatos e ações fizeram funcionar cada docência em formação (ou em de-formação).

Certamente, o que se fez mais produtivo não foi o conteúdo da aula em si, ou uma maneira padrão para pensar as relações entre arte contemporânea e ensino das artes visuais - o que, inclusive, seria impossível em apenas algumas horas -, mas a suspensão de noções e conceitos dados, prontos, estanques, para que formulássemos concepções singulares em um coletivo. Para que, ao atiçarmos uma vontade de pesquisa, retroalimentássemos nossas questões com outras tantas problemáticas e assim a aula pudesse continuar reverberando em cada um de nós, mesmo após a finalização daquele espaço/tempo determinado.

\section{Nota 2. Pesquisa em docência, docência em pesquisa}

Tenho insistido, especialmente junto aos meus alunos, que é pela pesquisa e na pesquisa que nos constituímos próximos daquilo que chamamos de "bons" professores. É a pesquisa que nos faz estar sempre em movimento e não acreditar facilmente em modelos estanques, inclusive daquilo a que nomeamos "bom". É a pesquisa que nos faz repudiar fórmulas prontas de "como dar uma aula", de como "ser", "estar", "fazer", "produzir", "incluir". Todos esses, como tantos outros, são verbos que a mim só fazem sentido em uma aula, na docência, na pesquisa e, por sua vez, no universo desse texto, se estiverem associados a uma espécie de metaestabilidade que defasa continuamente certezas e abarca estados de dúvida, de problematização e de suspensão de receituários dados.

Revista Digital do LAV - Santa Maria - vol. 9, n. 2, p. 61 - 74. - mai./ago. 2016 ISSN 1983 - 7348 
Podemos fazer listas e mais listas puramente empíricas de técnicas bem-sucedidas (sabe-se lá o que é isto!); podemos, até mesmo, fazer um catálogo de nossas aulas ou currículos prediletos; mas o que não podemos fazer é fornecer uma fórmula para compor uma aula, currículo, melodia mozartiana, livro beckettiano, etc. [...] Se ninguém pedir e ninguém oferecer essas receitas, teremos, talvez, afastado o extremo tédio que cansa a professoralidade e as besteiras disseminadas sobre metodologia, didática, currículo (CORAZZA, 2012, p. 46-47).

O que chamo de "bom" aqui, portanto, não é um padrão a ser seguido, como uma imagem dogmática do pensamento (DELEUZE, 2006) sempre em dívida porque sempre inalcançável, mas um processo plenamente possível e praticável, contínuo, mobilizador do corpo e do próprio pensar, da própria pesquisa, a qual se dá por vias singulares. $\mathrm{O}$ que pode ser bom (potente) para mim e para os meus alunos? O que nos afeta enquanto coletivo e nos coloca a criar, a indagar, a encontrar vias diversas para certas problemáticas? Assim, aquilo que chamamos de

[...] boa aula (no sentido tradicional) pode ser uma aula extremamente ruim; isto é, improdutiva, conservadora, obstaculizadora ou impeditiva da criação, da invenção, da fabricação do novo. [...] Não há regras nem soluções universais. Cada professor sabe como proceder e tem uma ideia mais ou menos precisa do que quer fazer (CORAZZA, 2012, p. 25).

Associam-se a esse repúdio as "boas receitas de uma aula" e ao ideal do que seria um "bom professor", também a rejeição de um ideal de pesquisa, de maneiras de pesquisar e de ser pesquisador.

Tenho pensado, ainda com Corazza (2013, p. 94), que o pesquisador não necessariamente "integra uma elite". Ou seja, nessa concepção, não há um docente (geralmente universitário) que pesquise e outro (geralmente o do "chão da escola") que apenas aplique ou reproduza os achados mais ou menos viáveis dessas investigações legitimadas como científicas. Há docentes. E porque há docentes há docência e há, desse modo, pesquisa, para que essa docência se mantenha em movimento. Ainda que essa pesquisa nem sempre integre os grandes editais de produtividade científica ou não seja publicada nas mais variadas revistas acadêmicas. Ainda que nem sempre resultem em Trabalhos de Conclusão de Curso (TCCs), Monografias, Dissertações e Teses.

Mesmo que os sistemas educacionais (com os seus motivos), durante muito tempo, tenham inventado e divulgado o mito que existiria, de um lado, pouquíssimos intelectuais da educação que pesquisam; enquanto, de outro, haveria uma grande massa daqueles professores que somente ensinam [...] docência sem pesquisa não existe (CORAZZA, 2013, p. 93).

Revista Digital do LAV - Santa Maria - vol. 9, n. 2, p. 61 - 74. - mai./ago. 2016 ISSN 1983 - 7348

http://dx.doi.org/10.5902/1983734823513 
Qualquer tentativa de separação entre uma teoria e uma prática seria, portanto, inviável nessa esfera. A própria busca pela aula, pelos métodos, pelas matérias e conteúdos, pelas relações, pelas composições e traduções eminentemente criadoras (CORAZZA, 2012, 2013) entre matérias a ser ensinadas, já são aula, docência e pesquisa insurgindo e ao mesmo tempo se desfazendo, como trânsito contínuo do "Prazer de Aprender ao Desejo de Educar e vice-versa" (CORAZZA, 2012, p. 45).

Diz-se, assim, "de uma docência que procura; logo, que cria; e que é o canal da pesquisa" (CORAZZA, 2013, p. 94). Docência como plano onde se produzem "atos de criação pedagógica" (CORAZZA, 2013, p. 204), entendendo criação como "um processo de autocriação, de criação de si; ou seja, um diferenciar, diferenciando-se" (CORAZZA, 2013, p. 98).

Ensinar (fazendo pesquisa) e pesquisar (ensinando) consistem, dessa maneira, em criar soluções e, ao mesmo tempo, enigmas. Numa frase pronunciada ou escrita; no olhar ou no sorriso de alguém; num raio de luz; numa hora do dia, alguma coisa se passa, que não existia antes; e um novo, um inédito se faz, mesmo que não consigamos apreendê-lo (CORAZZA, 2013, p. 94).

Pensa-se uma aula (e/ou uma docência) que não existem sem pesquisa, vistas como zonas de criação, povoamento de territórios (de planos pensamentais) entre escritas, leituras e visualidades, essas enquanto potências que atravessam as ações de aprender e pesquisar arrastando territórios estáveis, desterritorializando-os e formulando para eles sempre novas zonas. Lugares para a invenção de problemas mobilizadores do pensamento, no contraponto da mera resolução de problemas $^{5}$, restringidora de multiplicidades.

As formas que essa aula-docência-pesquisa assume são inúmeras. Contudo, tanto nesse artigo, quanto nos projetos de pesquisa por mim coordenados e que ora mobilizam essa escrita, tenho olhado com mais atenção para as maneiras como essa amálgama aqui considerada indissociável - uma aula que faz aparecer uma docência, docências que pesquisam e, portanto, se presentificam em uma aula - insurge em meio a escritas, leituras e visualidades. É sobre tais materialidades que, na subseção a seguir, entendida como uma nota que atravessa transversalmente as zonas/notas anteriores (aula/docência - docência/pesquisa), procuro concluir esse texto deixando aberturas para produções futuras.

\footnotetext{
${ }^{5}$ Virgínia Kastrup em entrevista disponível em <https://www.youtube.com/watch? $v=S z 7-c L d g s V k>$. (Acesso em: maio 2016) diferencia invenção (mais próxima da noção de criação com a qual opero nesse texto) de criatividade, sendo a primeira, segundo a autora, não uma faculdade a mais (além da memória ou da aprendizagem, por exemplo), mas a potência que a cognição tem de se diferenciar de si mesma. Invenção seria, portanto, a invenção de sempre novos problemas no contraponto da criatividade como resolução única e estancamento de um determinado problema.
} 


\section{PARTE III}

\section{Nota 3. Nota transversal: povoamentos}

Escrevo e leio.

Encontro a escrita e a leitura como potências intensivas do texto que se interpenetram e se pressupõem.

Escrevo e leio.

$$
[\ldots]
$$

Sou eu mesmo o texto quando ele está diante de mim.

Escrevo e leio. Roubo, colo, recorto, raspo, borro, costuro, tatuo, destroço.

Escrevo e leio.

Estremeço cada palavra, racho cada partícula atômica de letra, encontro o infinito silencioso que entremeia balbucios e gagueiras.

Escrevo e leio.

No texto procuro a alegria como potência aumentativa e inventora de trânsitos e caminhos impensados no próprio pensamento.

Escrevo e leio.

(Fragmento de tese de doutorado, MOSSI, 2014, p. 74-75).

O excerto nos convida a pensar em ler e escrever como potências vivas e inseparáveis. Lê-se porque se escreve, escreve-se porque se lê. Escreve-se enquanto se lê e lê-se aquilo que se escreve. Resta saber o que temos chamado de leitura e de escrita, e como tais instâncias têm sido colocadas em funcionamento (em diálogo ou tensão), sobretudo no que concerne à aula-docência-pesquisa. A mim, ao menos, ainda parece caro avançar nessa discussão para pensarmos como temos inserido visualidades em meio a essa escrita/leitura.

Tenho procurado ponderar essas instâncias - da escrita, da leitura e das visualidades como lugares, como zonas para a produção do pensamento e, assim, da criação ou como "povoamento", ou seja, distantes de um uso que as restringe enquanto meros meios de representação ou recognição.

Virgínia Kastrup (ver nota 6) e Deleuze (2003a) nos convidam a pensar em um ato de invenção e/ou de criação distantes da ideia de criatividade como solução de problemas dados. Para ambos, invenção/criação se confunde com o próprio ato de pensar. São acontecimentos raros, os quais potencializam a cognição na direção de uma diferenciação de si mesma, no contraponto de mera recognição.

Pensar, portanto, não é nunca "descobrir" algo, descortinar alguma realidade escondida, tampouco produzir meras representações como clichês ou decalques, mas criar algo novo, como "um povo que falta" (DELEUZE, 2003a), daí a noção de "povoamento" presente nesse texto.

[...] o problema não é dirigir, nem aplicar metodicamente um pensamento preexistente por natureza e de direito, mas fazer que

Revista Digital do LAV - Santa Maria - vol. 9, n. 2, p. 61 - 74. - mai./ago. 2016 ISSN 1983 - 7348

http://dx.doi.org/10.5902/1983734823513 
nasça aquilo que ainda não existe [...]. Pensar é criar, não há outra criação, mas criar é, antes de tudo, engendrar 'pensar' no pensamento (DELEUZE, 2006, p. 213).

Escrita e leitura, associadas ou não a visualidades e vistas à luz de tal concepção do pensamento como criação são, logo, potências vivas e vivificantes de uma aula-docênciapesquisa que devém na contra direção de escritos e imagens como estrita representação e/ou ilustração.

Escreve-se não porque já se conhece algo que precisa ser registrado, cristalizado na escrita, mas justamente porque não há compreensão exata a respeito de alguma coisa e porque a criação/invenção de caminhos para tal, a busca em si, mostra-se, talvez, mais interessante do que a própria definição a ser encontrada. Lê-se não para ter certeza, para decifrar códigos, mas para que a certeza vacile e se estenda para uma zona de incerteza tal em que o impensado, o inusitado e as criações em redes de multiplicidade sejam possíveis. Utiliza-se imagens nessa escrita/leitura não para dizer de outro modo o que já foi dito, mas para criar fissuras, rasgões, tensões e friç̧ões entre as palavras, para que o pensamento seja acionado nesses vãos, capturando e deixando fugir aquilo que escapa às escritas/leituras.

Tais processos, os quais fazem funcionar uma máquina eminentemente inauguradora de algo novo, não são de modo algum inseparáveis ou pressupostos uns para os outros. Pensa-se (cria-se) para escrever e ler, escreve-se para ler e pensar (criar) e lê-se para pensar (criar) e escrever. Pensa-se a partir, com ou pelas imagens que atravessam e/ou são atravessadas pela escrita/leitura.

[...] para que as escolhas que fazemos dos conceitos, textos, livros, obras de outros passem para nós, é necessário defini-los como escritos por nós; e, ao mesmo tempo, torná-los outros, deformando-os por amor, desde que por eles fomos seduzidos. 0 que buscamos nos conceitos que desejamos é que alguma coisa ocorra: uma nova aventura, uma nova conjunção amorosa; e, por isso, a relação que estabelecemos com determinados conceitos do autor amado é a de que eles fiquem lá, como signos de nós próprios, inspirando-nos, a passar do Prazer de Ler ao Desejo de Escrever (CORAZZA, 2013, p. 18).

O novo que insurge, certamente não é um novo resultante da mente e da consciência de certo gênio criativo, mas de encontros fundamentais que ocorrem entre disparadores diversos, os quais constituem o escritor-leitor-visualizador/produtor de imagens, ao invés de serem determinados por ele. Há uma espécie de deformação nesse processo que faz da aula-docência-pesquisa algo necessariamente novo, ainda que repleta do já dito, já feito, já dado, já lembrado, já investigado.

Revista Digital do LAV - Santa Maria - vol. 9, n. 2, p. 61 - 74. - mai./ago. 2016 ISSN 1983 - 7348 http://dx.doi.org/10.5902/1983734823513 
Para Skliar (2014), leitura e escrita comungam de um sentido: o de fazer vacilar o Eu como categoria inquestionável. A leitura, segundo o autor, se configura enquanto uma experiência em que o "leitor põe à prova sua crença identitária na alteridade da leitura: a cada fragmento, a possibilidade de uma pergunta que começa sendo exterior e se interioriza até confundir alteridade com intimidade" (SKLIAR, 2014, p. 85). Já a escrita, relacionada a essa primeira, se qualifica "como convite a ir além de si mesmo, a sair, a livrar-se da própria modorra, um convite para abandonar o relato repetido, a identidade de si como centro do universo" (SKLIAR, 2014, p.109).

Utilizando tal perspectiva para olharmos uma escrita/leitura (com visualidades) em relação à aula-docência-pesquisa, teremos sempre uma rede no mínimo extensa de possibilidades, de amarrações, vias, acessos, tensões - como uma cartografia, um labirinto, uma colagem - por onde nos movimentamos e damos por assentadas certas concepções por breves espaços de tempo. Teremos somente velocidades diferentes de escoamento e cristalização daquilo que enunciamos coletivamente, mediante os agenciamentos que somos capazes de produzir rizomaticamente (DELEUZE; GUATTARI, 2011), a partir do que nos afeta.

Quantas vias de acesso há em um texto? Quantas formas são possíveis de lê-lo e, tornando-o nosso, de escrevê-lo? Quantos desdobramentos se colocam em escritas/leituras que abarcam essa zona de incerteza, de não plenitude, de uma totalidade falha, entrecortada? Costumo pensar naquele que escreve/lê, que captura visualidades para essa escrita/leitura, como o agrimensor de um espaço informe, inacabado, de um Fora absoluto onde nada "É" ainda, mas onde tudo poderá vir a ser (LEVY, 2011) de acordo com o modo com que tal e qual escrita/leitura associada (ou não) a visualidades puder ser rearticulada, rearranjada, de acordo com os limites impensados que o próprio pensamento enquanto criação nessas ações puder alcançar. As ações de escrever/ler qualquer coisa, incorporar visualidades a essa escrita/leitura em uma aula-docência-pesquisa seria, portanto, mais o trabalho de quem produz realidades mistas, híbridas, plurais, do que de quem reproduz uma única realidade engessada. É mais o trabalho de quem dissolve a si mesmo nessas ações, do que de um sujeito dotado de uma identidade plena capaz de produzir, significar e sobrecodificar enigmas e códigos.

\section{Referências}

AGAMBEN, Giorgio. O que é o contemporâneo? In: O que é o contemporâneo? e outros ensaios [tradução de Vinícius Nicastro Honesko]. Chapecó: Argos, 2009, p. 55-73. CORAZZA, Sandra Mara. O que se transcria em educação? Porto Alegre: UFRGS; Doisa, 2013.

Revista Digital do LAV - Santa Maria - vol. 9, n. 2, p. 61 - 74. - mai./ago. 2016 ISSN 1983 - 7348 http://dx.doi.org/10.5902/1983734823513 
(Org.). Didaticário de criação: aula cheia (Escrileituras - caderno de notas 3). Porto Alegre: UFRGS, 2012.

DELEUZE, Gilles. Diferença e repetição [tradução de Luiz Orlandi e Roberto Machado]. 2.ed. Rio de Janeiro: Graal, 2006.

Qu'est-ce que l'acte de création? In: Deux régimes de fous. Textes et entrétiens 1975-1995. Paris: Minuit, 2003a, p. 291-302.

Proust e os signos [Tradução de Antonio Piquet e Roberto Machado]. Rio de Janeiro: Forense Universitária, 2003b.

DELEUZE, Gilles; GUATTARI, Félix. Mil platôs: capitalismo e esquizofrenia, v. 1. 2.ed. [tradução de Ana Lúcia de Oliveira, Aurélio Guerra e Célia Pinto Costa]. Rio de Janeiro: Ed. 34, 2011.

. Mil platôs: capitalismo e esquizofrenia, v. 4. 2.ed. [tradução de Suely Rolnik]. São Paulo: Ed. 34, 2012.

. Mil platôs: capitalismo e esquizofrenia, v. 2 [tradução de Ana Lúcia de Oliveira e Lúcia Cláudia Leão]. São Paulo: Ed. 34, 1995.

FEIL, Gabriel Sausen. In: CORAZZA, Sandra Mara (Org.). Didaticário de criação: aula cheia (Escrileituras - caderno de notas 3). Porto Alegre: UFRGS, 2012, p. 63-65.

LEVY, Tatiana Salem. A experiência do fora - Blanchot, Foucault e Deleuze. Rio de Janeiro: Civilização Brasileira, 2011.

MARTINS, Raimundo. Imagem e processo de interpretação no contexto escolar. In: RODRIGUES, Edvânia B. T.; ASSIS, Henrique L. (Orgs.) O ensino de artes visuais: desafios e possibilidades contemporâneas. Goiânia: Secretaria da Educação e Governo do Estado de Goiás, 2009, p. 99-106.

MOSSI, Cristian Poletti. Um corpo-sem-órgãos, sobrejustaposições. Quem a pesquisa [em educação] pensa que é? Tese (Doutorado em Educação) Santa Maria: Programa de pós-graduação em educação (PPGE), Universidade Federal de Santa Maria, 2014.

SKLIAR, Carlos. Desobedecer a linguagem: educar [tradução de Giane Lessa] Belo Horizonte: Autêntica Editora, 2014.

TADEU, Tomaz. A filosofia de Deleuze e o currículo. (Coleção Desenrêdos; n.1). Goiânia, Faculdade de Artes Visuais, 2004.

1 Professor adjunto do Departamento de Ensino e Currículo (DEC) da Faculdade de Educação (Faced) da Universidade Federal do Rio Grande do Sul (UFRGS). Doutor em Educação pelo Programa de Pós-Graduação em Educação da Universidade Federal de Santa Maria, na linha de pesquisa Educação e Artes. Membro pesquisador do Grupo de Estudos e Pesquisas em Arte, Educação e Cultura (GEPAEC) e do Grupo de Estudo e Pesquisa em Arte e Docência - ARTEVERSA, ambos lotados no CNPq. Endereço eletrônico para contato: <cristianmossi@gmail.com>

Enviado em: 30 de maio de 2016. - Aprovado em: 01 de agosto de 2016.

Revista Digital do LAV - Santa Maria - vol. 9, n. 2, p. 61 - 74. - mai./ago. 2016 ISSN 1983 - 7348

http://dx.doi.org/10.5902/1983734823513 